\title{
Lymphomatoid papulosis associated with Hodgkin lymphoma
}

\section{Nao Kusutani', Junko Sowa-Osako', Kazuyoshi Fukai², Naoki Maekawa², Sakurako Arai ${ }^{1,3}$, Yuko Kuwae ${ }^{4}$, Masahiko Ohsawa ${ }^{4}$, Daisuke Tsuruta' ${ }^{1}$}

${ }^{1}$ Department of Dermatology, Osaka City University Graduate School of Medicine, Osaka, Japan, ${ }^{2}$ Department of Dermatology, Osaka City General Hospital, Osaka, Japan, ${ }^{3}$ Department of Dermatology, National Hospital Organization Osaka Minami Medical Center, Osaka, Japan, ${ }^{4}$ Department of Diagnostic Pathology, Osaka City University Graduate School of Medicine, Osaka, Japan

Corresponding author: Dr. Nao Kusutani, E-mail: naokusu@med.osaka-cu.ac.jp

Sir,

Lymphomatoid papulosis (LyP), a recurrent spontaneous regressing papulonodular skin eruption with a chronic course, is one of the CD30-positive lymphoproliferative disorders (LPDs), among which are primary cutaneous anaplastic large cell lymphoma (ALCL) and borderline cases. LyP is known to increase the risk of malignant lymphoma, such as mycosis fungoides, ALCL, and Hodgkin lymphoma (HL) [1-3]. HL is characterized by CD30-positive Hodgkin/ReedSternberg (HRS) cells and is rare among the East Asian population [4]. Herein, we report a Japanese case of LyP associated with HL.

A 79-year-old Japanese man with a history of HL in complete remission by chemoradiotherapy 10 years prior presented with a 7-mm-sized asymptomatic reddish nodule on his left eyelid for over 3 months (Fig. la). He also had scattered reddish papules on his trunk (Figs. 1b and 1c), which had waxed and waned for about 10 years. A skin biopsy from the eyelid showed atypical lymphoid cell proliferation in the dermis (Figs. 2a and 2b), and these atypical cells had HRS-like features with bilobed nuclei and abundant cytoplasm (Fig. 2c). Immunohistochemical staining revealed that the tumor cells were positive for CD3, CD4, and CD30 (Fig. 2d) and negative for CD8, CD15, CD20, PAX, and ALK. A biopsy specimen from the trunk lesion exhibited perivascular cell infiltration with large lymphoid cells (Figs. 2e - 2g) with the same immunohistochemical staining pattern. Retrospectively, the lymphoma cells in the lymph node diagnosed as HL were positive for CD15, CD30, and PAX and negative for CD3, CD4, CD8, CD20, and ALK. PET-CT imaging was negative for nodal and visceral lesions. These findings led to a definitive diagnosis of LyP for scattered skin lesions. The nodule on the eyelid was resected as it had remained unchanged for over 4 months. No recurrence was observed at the site of excision on the eyelid, and the nodules on the trunk have been stabilized with topical corticosteroid treatment for 2 years.

CD30-positive LPDs and HL both express CD30 and they could be the differential diagnosis of one another. The current consensus is that HL cells are derived from germinal center B cells and have the immunophenotypic features of CD15 and PAX positivity, whereas the ALCL cells are negative for both [5]. As skin infiltration in HL is rare and usually occurs adjacent to an enlarged lymph node, the scattered multiple nodules in the present case were not indicative of specific HL-associated skin lesions. Although patients with LyP have a good prognosis, they have been reported to have an increased risk of developing lymphoid malignancy. LyP may be preceded with or followed by a malignant lymphoma in 10-20\% of the patients [1-3]. HL is the one of the most common diseases associated with lymphomas reported in western countries; however, LyP associated with HL has not yet been reported in the Japanese population. The multiple cutaneous nodules in the present case with spontaneous regressing course were diagnosed as LyP, and the persistent nodule on his

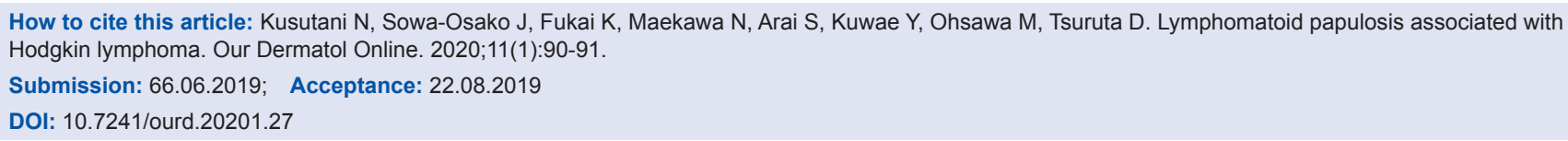



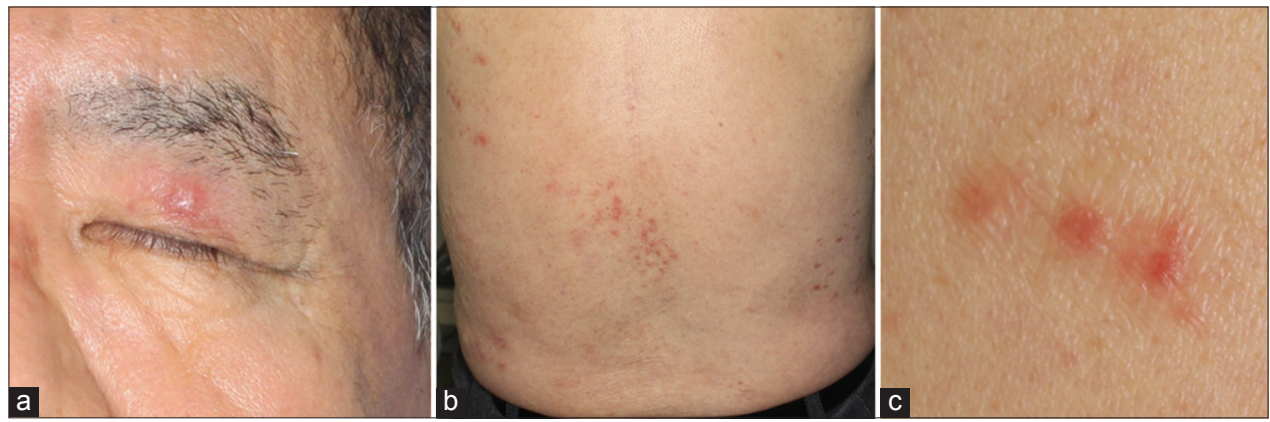

Figure 1: (a) The patient had a 7-mm-sized asymptomatic reddish nodule on his left eyelid at the first visit. (b and c) The patient also had scattered reddish papules on his trunk (lesions on the back and at close-up view, respectively).

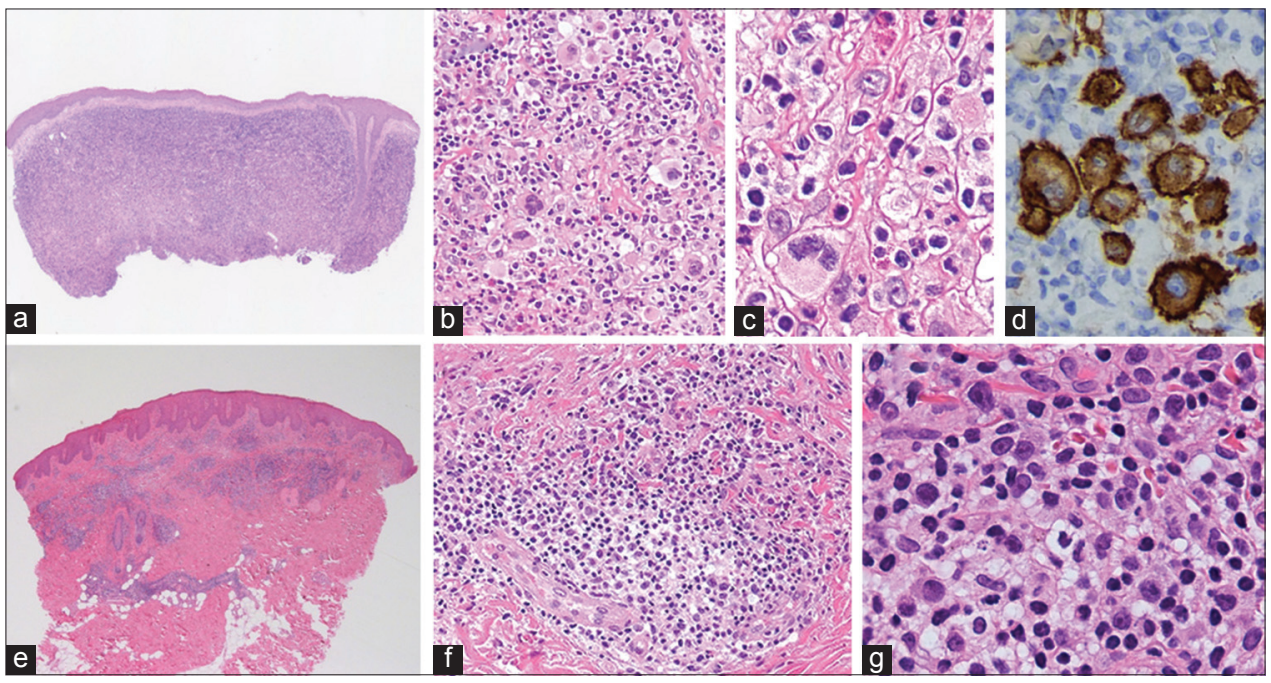

Figure 2: (a) The punch biopsy specimen from the eyelid showed diffuse and dense cell infiltration in the dermis (hematoxylin-eosin [HE], at scan magnification). ( $b$ and c) The tumor cells have large nuclei and abundant cytoplasm and some tumor cells have HRS-like figures with bilobed, double, or multiple nuclei (HE, $\times 100$ and $\times 400$, respectively). (d) The atypical lymphoid cells were CD30 positive (immunostaining for anti-CD30 antibodies, $\times 400)$. (e) The punch biopsy specimen from the trunk showed nodular perivascular cell infiltration (HE, at scan magnification). ( $f$ and $g$ ) The lymphoid cells with large nuclei scattered in the inflammatory cell infiltration (HE, $\times 100$ and $\times 400$, respectively).

eyelid as a borderline lesion that are likely associated with an HL history.

\section{Consent}

The examination of the patient was conducted according to the Declaration of Helsinki principles.

\section{REFERENCES}

1. Bekkenk MW, Geelen FA, van Voorst Vader PC, Geerts ML, van Vloten WA, et al. Primary and secondary cutaneous CD30(+) lymphoproliferative disorders: a report from the Dutch Cutaneous Lymphoma Group on the long-term follow-up data of 219 patients and guidelines for diagnosis and treatment. Blood. 2000;95:3653-61.

2. Cordel N, Tressières B, D’Incan M, Machet L, Grange F, Estève É, et al. Frequency and risk factors for associated lymphomas in patients with lymphomatoid papulosis. Oncologist. 2016;21:76-83.

3. Gan EY, Tang MB, Tan SH. Lymphomatoid papulosis: is a second lymphoma commoner among East Asians? Clin Exp Dermatol. 2012;37:118-21.

4. Huh J. Epidemiologic overview of malignant lymphoma. Korean J Hematol. 2012;47:92-104.

5. Stein H, Pileri SA, Weiss LM, Poppema S, Gascoyne RD, Jaffe ES. Hodgkin lymphomas: Introduction. In: Swerdlow SH, Campo E, Harris NL, et al (eds). WHO Classification of Tumours of Haematopoietic and Lymphoid Tissues, Vol 2, Revised $4^{\text {th }}$ edn. Lyon: International Agency for Research on Cancer. 2017:424-30.

Copyright by Nao Kusutani, et al. This is an open-access article distributed under the terms of the Creative Commons Attribution License, which permits unrestricted use, distribution, and reproduction in any medium, provided the original author and source are credited. Source of Support: Nil, Conflict of Interest: None declared. 